\title{
Note
}

\section{USE OF A COMPENSATION PARAMETER IN THE THERMAL DECOMPOSITION OF COPOLYMERS}

\author{
K.N. SOMASEKHARAN and V. KALPAGAM \\ Department of Inorganic and Physical Chemistry, Indian Institute of Science, Bangalore 560012 \\ (India)
}

(Received 2 April 1986)

During the past 25 years, thermal techniques have been widely used to study the kinetics of solid state decomposition reactions. In principle, one should find prodigious data on homopolymers, to facilitate the interpretation of the thermal decomposition behaviour of copolymers. During recent studies on poly(styrene-co-methyl methacrylate), however, it was found that the available data on polystyrene and poly(methyl methacrylate) was too inconsistent to be used with any level of confidence. Isothermal and nonisothermal experiments are found to yield differing kinetic parameters. Procedural factors, such as the heating rate, sample size, pretreatment of the sample, container shape and atmosphere, are implicated in the widely differing calculated parameters; the range of decomposition studied and the particular form of the equation used for data reduction also have an effect.

\section{RESULTS AND DISCUSSION}

The most widely used relations, e.g. the Coats-Redfern equation [1], vary the order parameter using $R_{x y}$ as the convergence criterion. The correlation coefficient is an insensitive function near $\mathrm{d} R_{x y} / \mathrm{d} n=0$ (see Table 1: $\mathrm{d} R_{x y} / \mathrm{d} n=2 \times 10^{-4}$ ) and the unavoidable uncertainty in experimental data can offset $n$ substantially. The calculated activation energy and preexponential factor are highly dependent on $n$ (see Table $1: \mathrm{d} E / \mathrm{d} n=20.9$, $\mathrm{d} \log A / \mathrm{d} n=8.3$ ).

In the example given in Table 2 , the copolymers are all synthesized in the same manner [2] and subjected to TG analysis under close conditions; samples in the mass range $(5.1 \pm 1.5 \mathrm{mg})$, subjected to the same pretreatment, are studied on one TG instrument (Sinku-Rico ULVAC TA-1500 system with TGD-5000), at the same heating rate $\left(5^{\circ} \mathrm{C} \min ^{-1}\right)$ and under the same atmosphere (static air). Experimental data between 20 and $80 \%$ weight loss are used for computation using the Coats-Redfern equation; the number of data points used per thermogram is $15 \pm 3$.

In spite of the consistency in sample preparation, experimental procedure and data handling, the convergence was widely different $(n=0.9-3.4)$. 


\section{TABLE 1}

Dependence of the calculated kinetic parameters on the order parameter

The compound used is poly(styrene-co-methyl methacrylate), sample SM-32C

\begin{tabular}{lllll}
\hline$n$ & $R_{x y}$ & $\begin{array}{l}E^{*} \\
\left(\mathrm{kcal} \mathrm{mol}^{-1}\right)\end{array}$ & $\begin{array}{l}A \\
\left(\mathrm{~min}^{-1}\right)\end{array}$ & $\begin{array}{l}S_{\mathrm{p}} \\
\left(\mathrm{kcal} \mathrm{mol}^{-1}\right)\end{array}$ \\
\hline 3.05 & -0.99944 & $65.3 \pm 0.6$ & $6.41 \times 10^{24}$ & 2.63 \\
3.25 & -0.99955 & $69.3 \pm 0.6$ & $2.53 \times 10^{26}$ & 2.62 \\
3.45 & -0.99959 & $73.4 \pm 0.6$ & $1.08 \times 10^{28}$ & 2.62 \\
3.65 & -0.99955 & $77.6 \pm 0.6$ & $5.00 \times 10^{29}$ & 2.61 \\
3.85 & -0.99950 & $81.8 \pm 0.7$ & $2.48 \times 10^{31}$ & 2.61 \\
\hline
\end{tabular}

Consequently, the calculated $E^{*}$ values are also divergent $\left(49.7 \mathrm{kcal} \mathrm{mol}^{-1}\right.$ $\pm 17.9 \%)$. When dealing with a series of similar samples, it is conventional to use the average $n$; when the average value of $n=1.8$ is used, the calculated $E^{*}$ values showed slightly less scatter $\left(49.5 \mathrm{kcal} \mathrm{mol}^{-1} \pm 15.6 \%\right.$; mean $R_{x y}=-0.99895$ ).

\section{TABLE 2}

Kinetic parameters for the thermal decomposition of poly(styrene-co-methyl methacrylate), calculated using the Coats-Redfern equation

\begin{tabular}{lllll}
\hline Sample & $R_{x y}$ & $n$ & $\begin{array}{l}E^{*} \\
\left(\mathrm{kcal} \mathrm{mol}^{-1}\right)\end{array}$ & $\begin{array}{l}S_{\mathrm{p}} \\
\left(\mathrm{kcal} \mathrm{mol}^{-1}\right)\end{array}$ \\
\hline SM-111 & -0.99985 & 1.60 & 54.3 & 2.86 \\
SM-112 & -0.99997 & 1.10 & 49.7 & 2.83 \\
SM-113 & -0.99975 & 1.80 & 46.3 & 2.79 \\
SM-114 & -0.99994 & 1.10 & 40.2 & 2.87 \\
SM-115 & -0.99995 & 1.10 & 44.1 & 2.82 \\
SM-116 & -0.99980 & 1.80 & 56.1 & 2.76 \\
SM-117 & -0.99990 & 1.80 & 52.8 & 2.77 \\
SM-118 & -0.99984 & 1.50 & 47.2 & 2.80 \\
SM-119 & -0.99990 & 2.00 & 48.6 & 2.82 \\
SM-1110 & -0.99996 & 0.90 & 37.3 & 2.84 \\
SM-1101 & -0.99994 & 1.55 & 38.6 & 2.86 \\
SM-31B & -0.99992 & 1.60 & 41.9 & 2.72 \\
SM-31C & -0.99995 & 3.30 & 50.8 & 2.66 \\
SM-31D & -0.99986 & 2.10 & 41.3 & 2.80 \\
SM-31E & -0.99973 & 2.05 & 52.9 & 2.67 \\
SM-32A & -0.99971 & 1.45 & 45.0 & 2.71 \\
SM-32B & -0.99985 & 1.90 & 62.5 & 2.66 \\
SM-32C & -0.99959 & 3.45 & 73.4 & 2.62 \\
SM-32D & -0.99968 & 1.90 & 49.6 & 2.69 \\
SM-32E & -0.99969 & 2.30 & 60.7 & 2.66 \\
Mean & -0.99984 & 1.82 & 49.7 & 2.76 \\
$+/-$ & 0.00011 & 0.65 & $17.9 \%$ & $2.90 \%$ \\
\hline
\end{tabular}


In an attempt to overcome some of these difficulties, and to make the available data amenable to comparison, we have introduced a parameter $\left(S_{\mathrm{p}}\right)$ defined as $E^{*} / \log A$. The $S_{\mathrm{p}}$ values calculated from the $E^{*}$ and corresponding $A$ (at $n=1.8)$ were very consistent $\left(S_{\mathrm{p}}=2.76\right.$; standard deviation $=2.2 \%$ )

The values of $E^{*}$ and $A$ for polystyrene and poly(methyl methacrylate) are collected from the literature. The calculated $S_{\mathrm{p}}$ for polystyrene is 2.99 and that for PMMA 2.76 (standard deviation less than 0.6\%), even though the experimental conditions vary widely and the reported $E^{*}$ for each differ. On comparing these with our experimental values for the copolymer, it seems apparent that the mechanism of its decomposition is the same as that of PMMA and different from that of PS.

From Table 1, it is seen that, for a given sample, $S_{\mathrm{p}}$ is insensitive to the influence of $n\left(\mathrm{~d} S_{\mathrm{p}} / \mathrm{d} n=-7 \times 10^{-2}\right)$; it is apparent, from Table 2, that the use of this parameter eliminates the scattering effect of $n$ in a set. The concept of an order of reaction is inconsistent with a reaction interface or any localized reaction. There have been attempts to avoid the order parameter from solid state kinetics before, notable examples being those of Jacobs and Kureishy [3] for isothermal studies and Ozawa [4] for non-isothermal experiments. The $S_{\mathrm{p}}$ parameter handles $n$ in a subtle way. Whereas the Jacobs-Kureishy method requires at least two isothermal runs at different temperatures, and the method by Ozawa requires non-isothermal runs at least at two different heating rates, the present method requires only a single non-isothermal run.

To make sure that we are not obliterating trends by introducing an insensitive parameter, we have looked at the dehydration of calcium oxalate monohydrate, the calculated kinetic parameters of which are known to depend on the heating rate (Table 3 ). This trend is observed in $S_{\mathrm{p}}$.

TABLE 3

Effect of heating rate on the calculated activation energies (in $\mathrm{kcal} \mathrm{mol}^{-1}$ ) for the decomposition of calcium oxalate ${ }^{\text {a }}$

\begin{tabular}{|c|c|c|c|c|}
\hline \multirow{2}{*}{$\begin{array}{l}\text { Heating rate } \\
{ }^{\circ} \mathrm{C} \text { min }^{-1}\end{array}$} & \multicolumn{2}{|c|}{ Stage $\mathrm{I}(n=0.65)^{\mathrm{b}}$} & \multicolumn{2}{|c|}{ Stage II $(n=0.50)^{\mathrm{c}}$} \\
\hline & $E^{*}$ & $S_{\mathrm{p}}$ & $E^{*}$ & $S_{\mathrm{p}}$ \\
\hline 1 & 55.6 & 2.07 & 55.9 & 3.95 \\
\hline 2 & 36.2 & 2.20 & 61.9 & 3.97 \\
\hline 5 & 26.1 & 2.35 & 63.0 & 3.97 \\
\hline 10 & 25.4 & 2.41 & 60.0 & 3.99 \\
\hline 20 & 22.4 & 2.47 & 56.5 & 3.98 \\
\hline 50 & 20.6 & 2.54 & 55.2 & 4.01 \\
\hline 100 & 17.5 & 2.68 & 58.1 & 4.02 \\
\hline
\end{tabular}

a Weight of $\mathrm{CaC}_{2} \mathrm{O}_{4} \cdot \mathrm{H}_{2} \mathrm{O}=5 \mathrm{mg}$. ${ }^{\mathrm{b}}$ Stage I: $\mathrm{CaC}_{2} \mathrm{O}_{4} \cdot \mathrm{H}_{2} \mathrm{O}=\mathrm{CaC}_{2} \mathrm{O}_{4}+\mathrm{H}_{2} \mathrm{O}$. ${ }^{\text {c Stage II: }}$ $\mathrm{CaC}_{2} \mathrm{O}_{4}=\mathrm{CaCO}_{3}+\mathrm{CO}$. 
The decomposition of calcium oxalate, on the other hand, is generally believed to be independent of the heating rate (Table 3 ). The activation energy calculated by the Coats-Redfern equation shows substantial scatter (standard deviation 5.3\%), obliterating any trend. Determination of $S_{\mathrm{p}}$ reduces the scatter (standard deviation $0.4 \%$ ), bringing to surface any possible weak trend.

It is generally accepted now that the theoretical significance that the kinetic parameters have for gas and liquid phase reactions cannot be extended to the solid phase. This is partly because the kinetics of many solid state reactions may not be determined by the reaction-rate; nucleation and diffusion might become rate-controlling mechanisms. However, kinetic equations based on the classical concepts, from homogeneous reactions, continue to be used widely for empirical usefulness. In this context, the parameter, $S_{\mathrm{p}}$, that gives proper weightage for the kinetic compensation [5] would make comparison of kinetic parameters derived under divergent conditions possible.

\section{ACKNOWLEDGEMENT}

This work was partly supported by the Council for Scientific and Industrial Research, New Delhi, India.

\section{REFERENCES}

1 A.W. Coats and J.P. Redfern, Nature (London), 201 (1964) 68.

2 C. Rami Reddy and V. Kalpagam, J. Polym. Sci., Polym. Phys. Ed., 14 (1976) 749.

3 P.W.M. Jacobs and A.R.T. Kureishy, J. Chem. Soc., (1964) 4718.

4 T. Ozawa, Bull. Chem. Soc. Jpn., 38 (1965) 1881.

5 J. Zsako, J. Therm. Anal., 9 (1976) 101. 